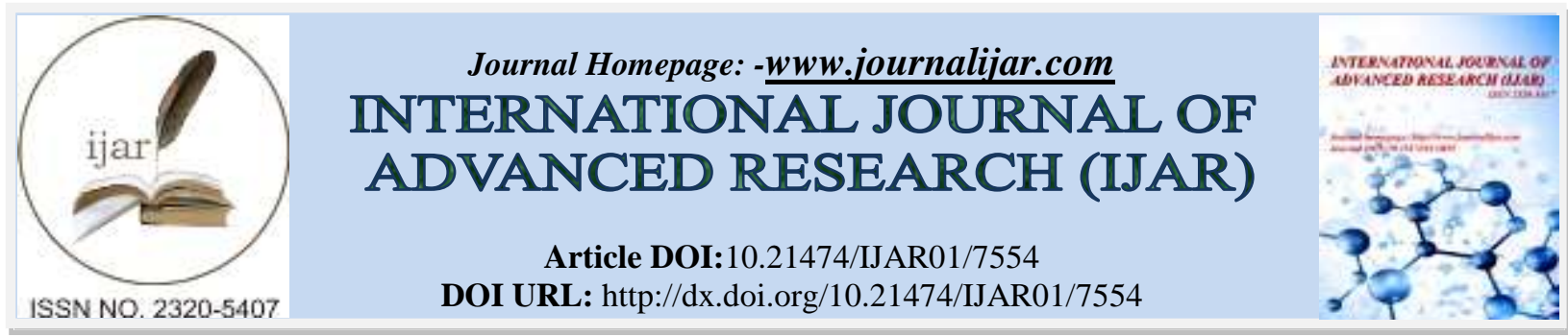

RESEARCH ARTICLE

\title{
INFLUENCE OF In/Cr SUBSTITUTIONS ON THE MAGNETIC PROPERTIES OF Ni-Zn FERRITES.
}

\author{
M. Ravikanth ${ }^{1,2}$, ${ }^{*}$ B. Chandra Sekhar ${ }^{3}$, P.S.V. Subba Rao ${ }^{1}$ and B. Parvatheeswara Rao ${ }^{1}$. \\ 1. Department of Physics, Andhra University, Visakhapatnam 530003, India. \\ 2. Rajah R.S.R.K. RangaRao College, Bobbili 535558, India. \\ 3. Vignan's Institute of Engineering for Women, Visakhapatnam 530046, India.
}

\section{Manuscript Info}

\section{Manuscript History}

Received: 13 June 2018

Final Accepted: 15 July 2018

Published: August 2018

Keywords:-

$\mathrm{Ni}-Z n$ ferrite, Magnetization, Initial permeability, Relative loss factor, High frequency applications.

\begin{abstract}
In/Cr substituted Ni-Zn ferrites were prepared by standard solid state reaction method using metal oxides to estimate the influence of substitutions on the magnetic properties of the $\mathrm{Ni}-\mathrm{Zn}$ ferrites. The ultrafine ground powders of the ferrite compositions were pressed into desired shapes and sintered at $1250^{\circ} \mathrm{C}$ for 4 hours in air atmosphere. $\mathrm{X}$ ray diffraction analyses of the samples confirm formation of single phase cubic spinel structures. Magnetic hysteresis loop measurements on the samples were made to study the magnetization behaviour and the obtained results indicate that the $\mathrm{In} / \mathrm{Cr}$ substitutions cause a decrease in magnetization with the increase in substituent's concentration. Initial permeability of the substituted ferrites exhibits stable frequency response up to $3 \mathrm{MHz}$ beyond which it exhibits a relaxation character while the relative loss factor has been found to be quite low up even up to the frequency of $40 \mathrm{MHz}$ while indicating their utility as elements for high frequency application systems.
\end{abstract}

Copy Right, IJAR, 2018, All rights reserved.

\section{Introduction:-}

Soft magnetic ferrites are an important class of magnetic materials in view of their large number of applications in several fields including information storage, microwaves, biomedical and consumer electronics. Among various ferrites $\mathrm{Ni}-\mathrm{Zn}$ ferrites are found to be the most versatile from the view point of their ease in preparation and scope for high frequency applications. The properties of ferrites are strongly dependent on the chemical composition as well as processing conditions. Many works had been reported so far [1-8] on the electrical and magnetic properties of Ni-Zn ferrites with different chemical modifications. Improvements in DC resistivity and dielectric properties were observed when the addition of tetravalent ions [1-4] to the basic Ni-Zn ferrite are carried out but at the same time there was slight degradation in the magnitude of the magnetic properties of these ferrets with such additions. Similarly, pentavalent additions in Ni-Zn ferrites [5,6] resulted in marginal improvements in magnetic properties while the divalent ions in minor additions in Ni-Zn ferrites $[7,8]$ caused a decrease in the electrical conductivity. However, it seems that not much attention has been paid in estimating the influence of trivalent ions particularly as replacements for iron ions in $\mathrm{Ni}-\mathrm{Zn}$ ferrites. It is therefore felt desirable to carry out a study of $\mathrm{Ni}-\mathrm{Zn}$ ferrites substituted with trivalent $\mathrm{In} / \mathrm{Cr}$ ions in place of iron ions to understand the influence of such substitutions, and also to compare between them to find out which one is more effective in improving the magnetic properties of the ferrites. 


\section{Experimental Details:-}

Two series of ferrite samples with compositions $\mathrm{Ni}_{0.3} \mathrm{Zn}_{0.7} \mathrm{In}_{\mathrm{x}} \mathrm{Fe}_{2-\mathrm{x}} \mathrm{O}_{4}(\mathrm{Ni}-\mathrm{Zn}-\mathrm{In})$ and $\mathrm{Ni}_{0.3} \mathrm{Zn}_{0.7} \mathrm{Cr}_{\mathrm{x}} \mathrm{Fe}_{2-\mathrm{x}} \mathrm{O}_{4}(\mathrm{Ni}-\mathrm{Zn}-\mathrm{Cr})$ where $\mathrm{x}$ ranges from 0.00 to 0.25 in steps of 0.05 were prepared by solid state reaction method by taking initial ingredients of $\mathrm{NiO}, \mathrm{ZnO}, \mathrm{Fe}_{2} \mathrm{O}_{3}, \mathrm{In}_{2} \mathrm{O}_{3}$ and $\mathrm{Cr}_{2} \mathrm{O}_{3}$ in desired proportions. Both the series were calcined at $900^{\circ} \mathrm{C}$ for 4 hours and subsequently sintered, after necessary mixing and wet grinding to evolve as uniform ultrafine particles, at $1250^{\circ} \mathrm{C}$ for 4 hours in air atmosphere. X-ray diffraction patterns taken on the powdered samples confirm single phase cubic spinel crystal structures for all the samples. The magnetic hysteresis loops were measured using Lakeshore vibrating sample magnetometer and the obtained were used to extract magnetization and coercivity parameters. Initial permeability and magnetic loss were measured using Keysight Impedance Analyzer.

\section{Results and Discussion:-}

Magnetization and coercivity:-

Magnetic hysteresis loops of both the Ni-Zn-In and Ni-Zn-Cr ferrite samples measured using vibrating sample magnetometer at room temperature under the external applied magnetic field range of \pm 15 kOe are shown in Figs. 1 and 2. It can be seen from the observed hysteresis loops that all the samples are magnetically soft with finite values of coercivity implying that the investigated Ni-Zn-In and Ni-Zn-Cr ferrites exhibit typical ferrimagneticbehaviour. However, it can also be seen from the loops that the In-substituted samples are not magnetically saturated by exhibiting rather low values of magnetization whereas the Cr-substituted samples are very much close to saturation by displaying relatively higher values of magnetization.

Though the samples exhibit lower magnetization values for all the samples their coercivities are interestingly shown to be resulted with rather low values. It implies that the studied $\mathrm{Ni}-\mathrm{Zn}$ ferrites with $\mathrm{In} / \mathrm{Cr}$ substitutions have become magnetically softer which indicates that there are no major pinning points to obstruct the rotation of magnetic spins. Also, additional degree of magnetic softness may be considered as promising for the utility of these materials in device applications.

The magnetic properties such as maximum magnetization and coercivityare extracted from the observed hysteresis loops, and their variations as a function of $\mathrm{In} / \mathrm{Cr}$ concentration (x) are shown in Figs. 3 and 4, respectively. The substitution of either diamagnetic In or paramagnetic $\mathrm{Cr}$ ions to replace the ferromagnetic $\mathrm{Fe}$ at each step of substitution in the Ni-Zn-In/Cr ferrite system is a gradual modification of the chemical composition in each system and thus a corresponding change in the magnetic behavior is expected.

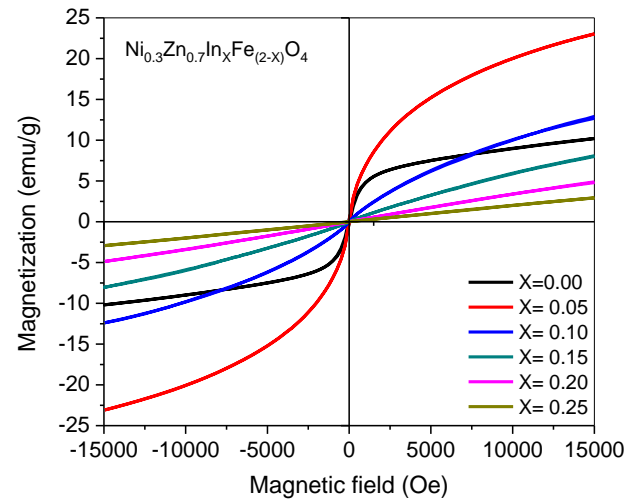

Fig.1. Magnetic hysteresis loops of $\mathrm{Ni}_{0.3} \mathrm{Zn}_{0.7} \mathrm{In}_{\mathrm{x}} \mathrm{Fe}_{2-\mathrm{x}} \mathrm{O}_{4}$ ferrites.

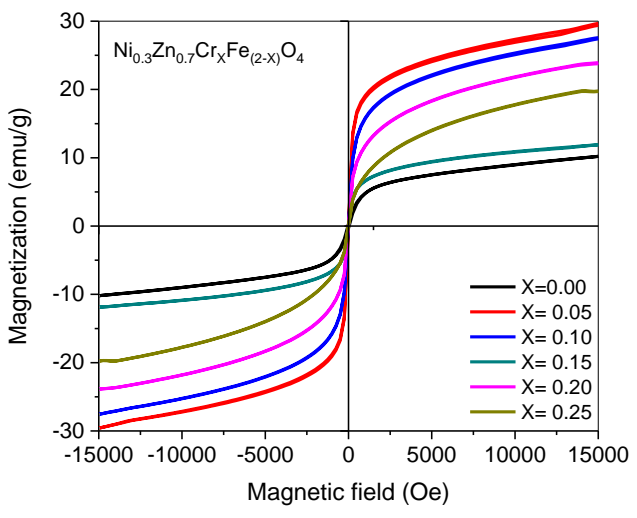

Fig. 2. Magnetic hysteresis loops of $\mathrm{Ni}_{0.3} \mathrm{Zn}_{0.7} \mathrm{Cr}_{x} \mathrm{Fe}_{2-\mathrm{x}} \mathrm{O}_{4}$ ferrites.

However, the incorporation of $\mathrm{In} / \mathrm{Cr}$ in the system seems to have larger influence by resulting in the magnetic strength of the material at the first step of substitution. Thereafter, there observed a rapid decrease in magnetization in In substituted samples whereas a slow decrease is noticed in $\mathrm{Cr}$ substituted samples. Nevertheless, the investigated samples have relatively shown smaller values of magnetization in comparison to the reported works of similar nature. On the other hand, the observed coercivities of all the substituted samples are very low indicating the additional degree of magnetic softness associated with only the presence of $\mathrm{In}$ and $\mathrm{Cr}$ ions in both the ferrite systems. This is because the undoped or basic Ni-Zn ferrite has experienced relatively higher value of coercivity. It 
implies that the In and $\mathrm{Cr}$ substitutions in $\mathrm{Ni}-\mathrm{Zn}$ ferrite systems help in realizing magnetic softness perhaps due to producing materials with almost negligible hindrances and pinning points for rotation of magnetic spins in the field direction and also for movement of domain walls in tune with the alterations of the applied magnetic field. Further, since the coercivity is dependent up on anisotropy and microstructure, the observed low coercivities for the substituted samples in both the ferrite systems indicate the In and $\mathrm{Cr}$ ions are helpful in decreasing the net anisotropy of the system. This behavior is highly solicited for device applications as it consumes not only less space as well as less power. In addition, it can also be seen from the figures that the trends of magnetization and coercivitybehaviours in both the ferrite systems are almost opposite to each other implying that the magnetization processes are complimented by the anisotropic nature of the samples and the corresponding microstructures are described in the previous chapter.

The observed variations of the magnetization with $\mathrm{In} / \mathrm{Cr}$ substitutions in both Ni-Zn-In and N-Zn-Cr ferrites are enoughly indicative that the magnetization processes in these materials are dominated mainly by spin rotations rather than domain wall motions. A phenomenon of this kind could be possible with the complete dissolution of substituent in the ferrite system. This is evident particularly with Cr substitutions as those samples exhibit relatively larger values of magnetization.

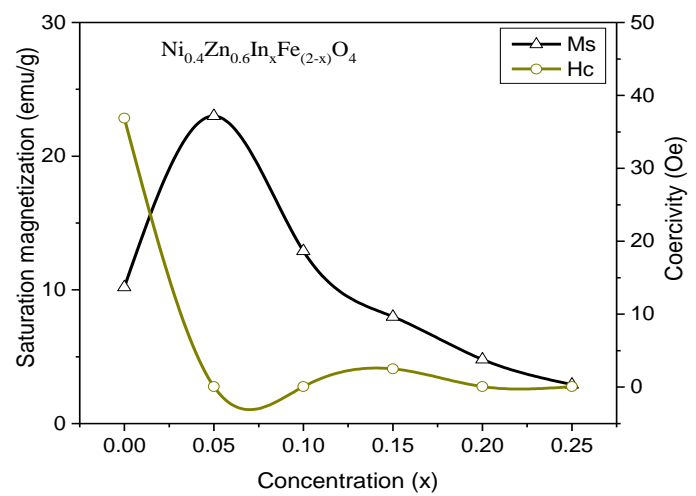

Fig. 3:-Variation of maximum magnetization and coercivity in Ni-Zn-In ferrites.

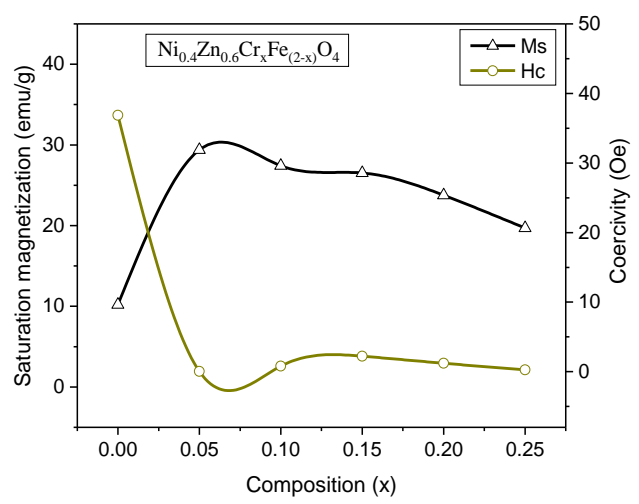

Fig. 4:-Variation of maximum magnetization and coercivity in $\mathrm{Ni}-\mathrm{Zn}-\mathrm{Cr}$ ferrites.

At the same time, limitations in the dissolution of In ions in these materials, as described in in the previous chapter in XRD patterns, are tend to hinder the rotational processes and consequently contribute to lower the magnetizations. The observed results are in accordance with these considerations, and similar results of magnetization mechanisms dominated by spin rotations in ferrites were also reported earlier [9].

\section{Compositional dependence of initial permeability:-}

The variations of initial permeability $\left(\mu_{\mathrm{i}}\right)$ at $100 \mathrm{kHz}$ with $\mathrm{In} / \mathrm{Cr}$ concentration $(\mathrm{x})$ for both Ni-Zn-In and Ni-Zn-Cr ferrites are shown in Fig. 5. The permeability continuously decreases with the increase in substituent concentration in both the systems. However, the decrease has been quite rapid up to $\mathrm{x}=0.10$ and thereafter the decrease has been slowed down in both the systems. Nevertheless, the permeability of any of the substituted samples in both the ferrite systems is much lower compared to that of the permeability of the basic Ni-Zn ferrite.

It is well known that the permeability of a material depends not only on chemical composition, but also on the microstructural modifications of the samples. In the present study, the microstructural aspects such as density, porosity (inter or intra granular pores in between or inside the grains) and the grain size of these materials are characterized without any abnormal behavior. So, the observed microstructures might not be responsible for the steep decrease in permeability in any of the ferrite systems. On the other hand, since the permeability is directly proportional to saturation magnetization for the contributions of spin rotations [10] and proportional to the square of the saturation magnetization for the contributions of domain wall motions [11], the observed magnetization values are examined to find out whether the magnetization behavior can explain the permeability variations in these In/Cr substituted ferrites. It may be mentioned here for all the substituted samples in Ni-Zn-In ferrite system, except for the first step of substitution, the magnetization decreases and consequently a decrease in permeability could be understood. On the other hand, the $\mathrm{Ni}-\mathrm{Zn}-\mathrm{Cr}$ ferrite system resulted in larger values of magnetization compared to 
the unsubstituted sample $(\mathrm{x}=0.00)$ and thus the permeability is expected to display relatively larger values with $\mathrm{Cr}$ substitutions, if the magnetization values were the predominant cause for permeability variations in this system. But, the observed permeability behavior is contrary to our expectations, and thus the variations in permeability must be governed by some other mechanism. Besides, the $\mathrm{Cr}$ and $\mathrm{In}$ ions are known to bring about modifications in anisotropy constant and magnetostriction $[12,13]$, which are inversely related to the permeability [14], they need to be explored to understand the permeability variations.

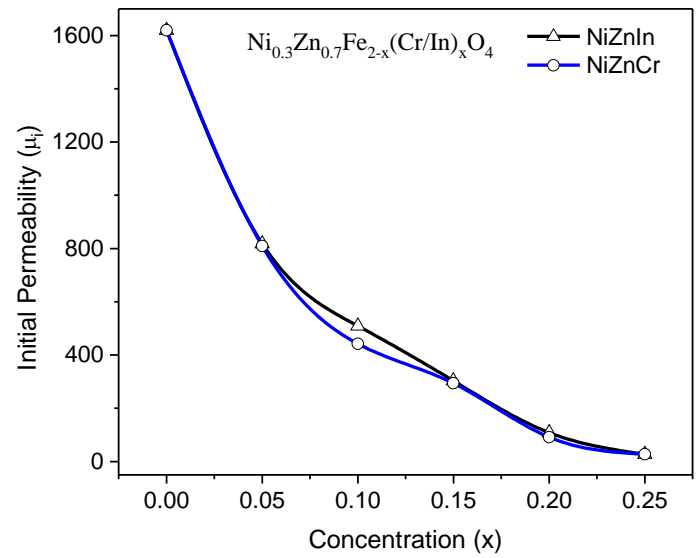

Fig. 5:-Variation of initial permeability as a function of $\mathrm{In} / \mathrm{Cr}$ concentration $(\mathrm{x})$ in $\mathrm{Ni}_{0.3} \mathrm{Zn}_{0.7}(\mathrm{In} / \mathrm{Cr})_{\mathrm{x}} \mathrm{Fe}_{2-\mathrm{x}} \mathrm{O}_{4} \mathrm{ferrites}$.

Consequently, an attempt has been made to calculate the anisotropy constants for all the samples in both these ferrite systems as the anisotropy modifications are known to influence the permeability. According to the Globus model [15], reversible domain wall motions mainly contribute to modify the magnitude of initial permeability. The relation between initial permeability, magnetization, grain size and anisotropy is represented by

$$
\left(\mu_{\mathrm{i}}-1\right)_{\mathrm{c}}=M_{s}^{2} \mathrm{D}_{\mathrm{m}} /\left|K_{l}\right|
$$

where $M_{s}$ is the saturation magnetization, $\mathrm{D}_{\mathrm{m}}$ is the average grain diameter, and $\mathrm{K}_{1}$ is the magneto crystalline anisotropy. Using the above equation, the magneto crystalline anisotropy values have been estimated for all the samples and the obtained values of Ni-Zn-In and Ni-Zn-Cr ferrites are listed in Tables 1 and 2, respectively along with the values of the density, grain size, magnetization and permeability for all the samples.

The variation of $\mathrm{K}_{1}$ can be understood on the basis of single-ion anisotropy model (12), according to which the Fe ${ }^{3+}$ ions at the tetrahedral and octahedral sites for the basic Ni-Zn ferrite $(\mathrm{x}=0.00)$ contribute to $\mathrm{K}_{1}$, leaving out the $\mathrm{Ni}^{2+}$ ions contribution. The contribution from A-site $\mathrm{Fe}^{3+}$ ions to the total anisotropy is positive while that of the B-site $\mathrm{Fe}^{3+}$ ions is negative but larger. Moreover, it is generally believed that the increase in zinc content in a ferrite decreases the net anisotropy [16]. On substitution of $\mathrm{Cr}$ for Fe in $\mathrm{Ni}-\mathrm{Zn}-\mathrm{Cr}$ ferrite system, the substitution has lead to a continuously increasing trend which has a profound influence on magnetic permeability and losses. It could perhaps be associated with a simultaneous generation of a small quantity of $\mathrm{Fe}^{2+}$ ions which in turn possess a large positive anisotropy and contribute to a large extent to the overall value of $\mathrm{K}_{1}$ [17] since the total anisotropy of the material is the sum of the contributions of all the individual ions in a given ferrite system.

Table 1:-Density, grain size, magnetization $\left(M_{s}\right)$, crystalline anisotropy constant $\left(K_{l}\right)$ and initial permeability $\left(\mu_{i}\right)$ for the Ni-Zn-In ferrites.

\begin{tabular}{|c|c|c|c|c|c|}
\hline Concentration (x) & Density g/cm & Grain size $\mu \mathrm{m}$ & $M_{s}$ emu/g & $K_{l} \times 10^{6} \mathrm{erg} / \mathrm{cm}^{3}$ & $\mu_{\mathrm{i}}$ \\
\hline & & & & & at 1 \\
\hline 0.00 & 5.0911 & 2.15 & 10.20 & 0.35 & 637.4 \\
\hline 0.05 & 5.1287 & 2.35 & 23.00 & 3.86 & 321.8 \\
\hline 0.10 & 5.1851 & 2.52 & 12.91 & 2.10 & 200.3 \\
\hline 0.15 & 5.2424 & 3.09 & 7.99 & 1.65 & 119.6 \\
\hline 0.20 & 5.2784 & 2.79 & 4.37 & 1.24 & 42.9 \\
\hline 0.25 & 5.2875 & 2.65 & 2.91 & 2.10 & 10.7 \\
\hline
\end{tabular}


Table 2:-Density, grain size, magnetization $\left(M_{s}\right)$, crystalline anisotropy constant $\left(K_{l}\right)$ and initial permeability $\left(\mu_{i}\right)$ for the $\mathrm{Ni}-\mathrm{Zn}$-Cr ferrites.

\begin{tabular}{|c|c|c|c|c|c|}
\hline Concentration (x) & Density $\mathrm{g} / \mathrm{cm}^{3}$ & Grain size $\mu \mathrm{m}$ & $M_{s} \mathrm{emu} / \mathrm{g}$ & $K_{l} \times 10^{6} \mathrm{erg} / \mathrm{cm}^{3}$ & $\mu_{\mathrm{i}}$ at $1 \mathrm{MHz}$ \\
\hline 0.00 & 5.0911 & 2.15 & 10.20 & 0.35 & 637.4 \\
\hline 0.05 & 5.1146 & 2.34 & 29.39 & 6.35 & 318.3 \\
\hline 0.10 & 5.1208 & 2.84 & 27.42 & 12.28 & 173.9 \\
\hline 0.15 & 5.1499 & 3.16 & 26.53 & 19.22 & 115.7 \\
\hline 0.20 & 5.1887 & 2.45 & 23.78 & 38.59 & 35.9 \\
\hline 0.25 & 5.2084 & 2.34 & 19.71 & 84.96 & 10.7 \\
\hline
\end{tabular}

\section{Frequency dependence of permeability:-}

Frequency dependence of initial permeability for all the samples in both the ferrite systems are shown in Figs 6 and 7. The basic Ni-Zn ferrite with $x=0.00$ sample with relatively higher permeability exhibits a fairly stable response up to $2 \mathrm{MHz}$ beyond which it decreases sharply. However, the permeabilities of all the substituted samples in both the ferrite systems, due to the reduction in their magnitude of permeabilities, have been stable few more megahertz and thereafter the permeability is observed to decrease sharply in all the samples. The observed permeability behavior is indicative of relaxation. Naturally, the frequency at which the relaxation takes place has been observed to be higher for lower permeability ferrite samples.

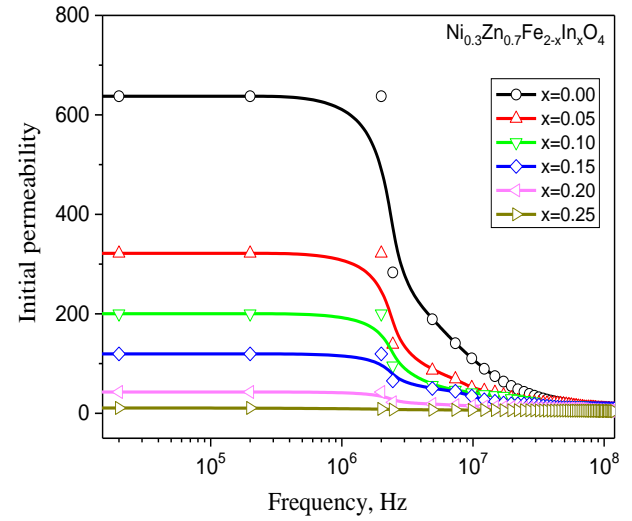

Fig. 6. Frequency dependence of initial permeability of $\mathrm{Ni}_{0.3} \mathrm{Zn}_{0.7} \mathrm{In}_{\mathrm{x}} \mathrm{Fe}_{2-\mathrm{x}} \mathrm{O}_{4}$ ferrites.

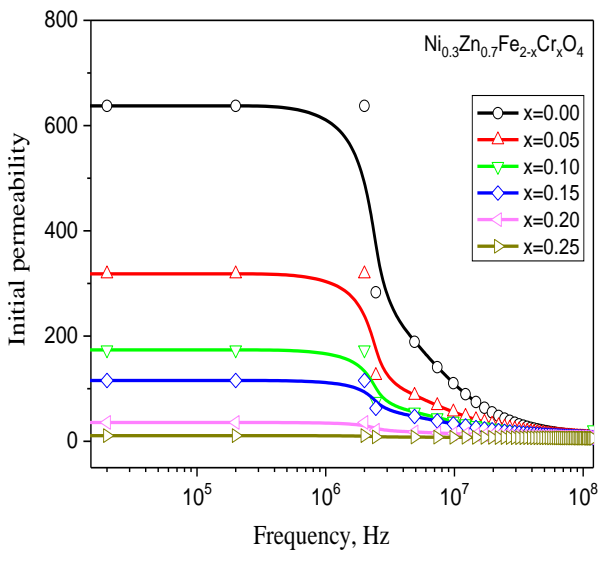

Fig. 7. Frequency dependence of initial permeability of $\mathrm{Ni}_{0.3} \mathrm{Zn}_{0.7} \mathrm{Cr}_{\mathrm{x}} \mathrm{Fe}_{2-\mathrm{x}} \mathrm{O}_{4}$ ferrites.

\section{Relative magnetic loss factor:-}

Figs. 8 and 9 show the frequency dependence of relative loss factor $\left(\tan \delta / \mu_{\mathrm{i}}\right)$ for various concentrations of $\mathrm{In} / \mathrm{Cr}$ in Ni$\mathrm{Zn}-\mathrm{In}$ and $\mathrm{Ni}-\mathrm{Zn}-\mathrm{Cr}$ ferrites, respectively. The tan $\delta / \mu_{\mathrm{i}}$ has been observed to display typical lossy behavior and the obtained values are rather low for all the samples at higher frequencies. The frequency at which the $\tan \delta / \mu_{\mathrm{i}}$ value is minimum is called the threshold frequency [18]. In general, the tan $\delta / \mu_{\mathrm{i}}$ values observed in the present work are of the order of $10^{-4}$ in the high frequency region ranging from $4 \mathrm{MHz}$ to $40 \mathrm{MHz}$ indicating the usefulness of these materials for device applications. This also suggests that the $\mathrm{In} / \mathrm{Cr}$ substitutions in $\mathrm{Ni}-\mathrm{Zn}$ ferrites are effective in reducing the losses, which could perhaps be due to increased uniformity, structural homogeneity and fine grained microstructures obtained from the advantages offered by the sol-gel autocombustion method in preparation of the initial powders. 


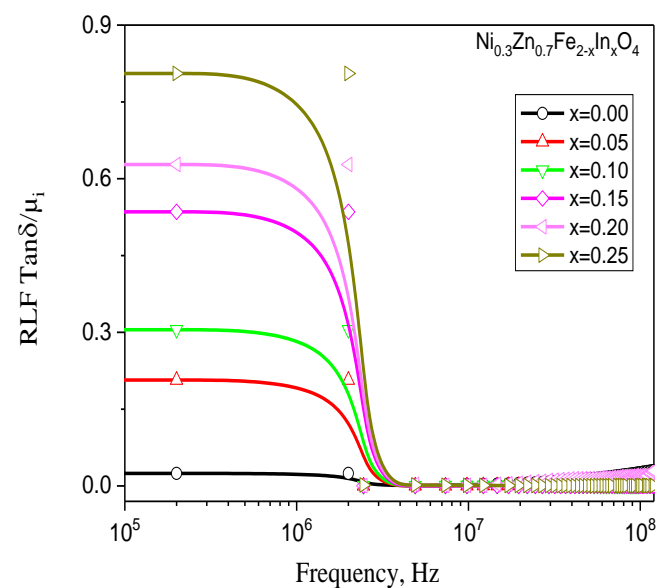

Fig. 8. Frequency dependence of relative magnetic loss factor for different In concentrations $(x)$ in $\mathrm{Ni}_{0.3} \mathrm{Zn}_{0.7} \mathrm{In}_{\mathrm{x}} \mathrm{Fe}_{2-\mathrm{x}} \mathrm{O}_{4}$ ferrites.

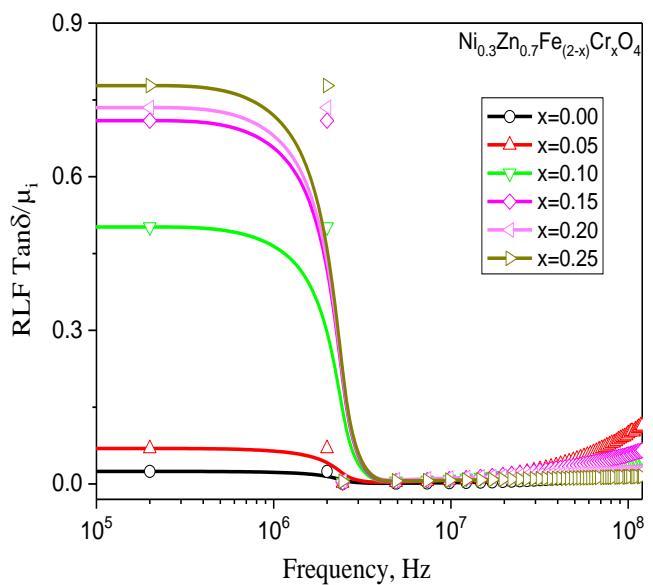

Fig. 9. Frequency dependence of relative magnetic loss factor for different $\mathrm{Cr}$ concentrations (x) in $\mathrm{Ni}_{0.3} \mathrm{Zn}_{0.7} \mathrm{Cr}_{\mathrm{x}} \mathrm{Fe}_{2-\mathrm{x}} \mathrm{O}_{4}$ ferrites.

It is interesting to note down that in the present study the most promising aspect that lies is, despite the large decrease in permeability compared to the undoped $\mathrm{Ni}-\mathrm{Zn}$ ferrite, the relative loss factor has been observed to show fairly improved results up to the frequencies of $40 \mathrm{MHz}$ for all the substituted samples. This may be partly due to the improvements in anisotropy constant and resistivity, to be discussed in chapter 6, apart from microstructural modifications as a result of $\mathrm{In} / \mathrm{Cr}$ substitutions for iron in $\mathrm{Ni}-\mathrm{Zn}$ ferrites.

For ferrites to be useful as inductor and transformer materials, the tan $\delta / \mu_{\mathrm{i}}$ values should be as low as possible over a wide frequency range. Thus, the samples presented in this work are useful in this regard. The tan $\delta / \mu_{\mathrm{i}}$ values observed in our work are comparable to some of the reported values in the literature [19,20] with the benefit of elevating the threshold frequencies towards a higher limit in all the substituted samples in these ferrites.

It can therefore inferred from the above that the data in the present study suggests that the obtained magnetic parameters such as saturation magnetization and coercivity coupled with magnetic permeability and loss factors help to enhance the frequency response of the materials relatively to a higher level. Further, since the In/Cr substitutions in the studied $\mathrm{Ni}-\mathrm{Zn}$ ferrites show good performance in the relative loss factors up to several megahertz, and thus they are useful for applications of power transformer cores and inductors.

\section{Conclusions:-}

The Ni-Zn-In and Ni-Zn-Cr ferrites prepared by standard solid state reaction method have been investigated to understand their magnetic performance. The incorporation of $\mathrm{In} / \mathrm{Cr}$ ions for $\mathrm{Fe}$ ions in $\mathrm{Ni}-\mathrm{Zn}$ ferrites has been marked by a significant reduction in relative loss factor. This decrease could perhaps be due to reduction of eddy current losses at high frequencies which is a natural consequence of increased resistivitiy. Also, the In/Cr substitutions could well favorable changes in anisotropic contributions in these ferrites leading to rather low core losses at high frequencies, which in turn resulting in increasing their viability for use in applications at such $\mathrm{MHz}$ frequencies.

\section{Acknowledgements:-}

Two of the authors (M. Ravikanth and B. Chandra Sekhar) thank the managements of the institutes where they work for the support and encouragement extended during the course of the work. 


\section{References:-}

1. W.A. Bayoumy, M.A. Gabal, J. Alloys Compd. 506 (2010) 205-209.

2. C.Venkatarajua, G. Sathishkumar, K. Sivakumar, J. Magn. Magn. Mater. 322 (2010) 230-233.

3. J. Smit and H. P. J. Wijn, Ferrites (Philips Technical Library, Eindhoven,(1959) 73.

4. M. Sertkol, Y. Koseoglu, A. Baykal, H. Kavas, A. Bozkurt, M.S. Toprak, J. Alloys Compd. 486 (2009) 325329.

5. B. ParvatheeswaraRao, K. H. Rao, J. Mater. Sci. Letts. 22, (2003) 1607- 1608.

6. B. ParvatheeswaraRao, B. Dhanalakshmi, S. Ramesh, P. S. V. SubbaRao, J. Magn. Magn. Mater. 456 (2018) 444-450.

7. S.G. Doh, E.B. Kim, B.H. Lee, J.H. Oh, J. Magn. Magn. Mater. 2238 (2004) 272-276.

8. A. Pradeep, P. Priyadharsini, G. Chandrasekaran, J. Magn. Magn.Mater. 320 (2008) 2774-2779.

9. N.D. Chaudhari, R.C. Kambale, J.Y. Patil, S.R. Sawant, S.S. Suryavanshi, Mater. Res. Bull. 45 (2010) 17131719.

10. S. Ramesh, B. Chandra Sekhar, P. S. V. SubbaRao, B. ParvatheeswaraRao, Ceramics Intl. 40 (2014) 87298735 .

11. T. Nakamura, J. Appl. Phys. 88 (2001) 348.

12. S. Chikazumi, S. Charap, Physics of Magnetism, John Wiley \& Sons, 1964

13. R. Gerber, G. Elbinger, J. Phys. C: Solid State Phys. 3 (1970) 1363

14. J.G.M. de Lau, Philips Res. Rep. Suppl. 6 (1975).

15. A.Globus, P. Duplex, M. Guyot, IEEE Trans. Magn, 7 (1971) 617-621.

16. L. K. Leung , B. J. Evans, A. H. Morrish , Phys. Rev. B 8, (1973) 29-43 .

17. G. S. N. Rao, O. F. Caltun, K. H. Rao, P. S. V. SubbaRao, B. ParvatheeswaraRao, J. Magn. Magn. Mater. 341 (2013) 60-64.

18. A.Verma, T.C. Goel, R.G. Mendiratta, P. Kishan, J. Magn. Magn. Mater. 208 (2000) 13-19

19. Amarendra K. Singh, Abhishek K. Singh, T.C. Goel, R.G. Mendiratta, J. Magn. Magn. Mater. 281(2004) 276280.

20. R.V. Mangalaraja, S. Ananthakumar, P. Manohar, F.D. Gnanam, Mater. Sci. Engg. A 355, (2003) 320-324. 